\title{
HACIA UNA TEORÍA DE LAS CATÁSTROFES MÍNIMAS ${ }^{34}$
}

\author{
Towards a Theory of Minimal Catastrophes
}

\author{
Félix Duque \\ (UAM, España)
}

Sería necesario hacer acopio de optimismo para no estar en el fondo de acuerdo -a pesar de lo apocalíptico de la terminología-, con un pensador como Heidegger, cuando éste nos describe la siguiente situación de su época: "por doquier hay conmociones políticas, crisis, catástrofes, penuria: todo ello, propio de la miseria social de nuestros días, del desbarajuste político, la impotencia de la ciencia, la vacuidad del arte, la carencia de suelo de la filosofía, la falta de fuerza de la religión." 35 Y el desánimo cunde aún más cuando constatamos que esas tremendas palabras han sido pronunciadas en el curso de invierno de 1929/30: hace más de 70 años, pues, antes de la terrible Segunda Guerra Mundial, de la Guerra Fría y sus secuelas.

Y mucho antes también, desde luego, de la última catástrofe: no tanto la caída de las Twin Towers el 11 de septiembre de 2001, cuanto la consiguiente destrucción de un orden (por parte igualmente, y sobre todo, de la potencia atacada) que parecía haberse asentado y expandido mundialmente tras el derrumbamiento (por nadie considerado catastrófico) del llamado "socialismo real" y, por ende, del último metarrelato capaz de enfrentarse con su mensaje emancipatorio y humanista a las dos fuerzas ahora pujantes: el capitalismo neoconservador y el fundamentalismo religioso.

Preciso es señalar enseguida que, de acuerdo con el credo fundamentalista (y no me refiero sólo, obviamente, al islámico), la catástrofe de la Historia (la catástrofe que es la Historia) resultaría paradójicamente aceptable para esa turbia ideología, y más: deseable, en cuanto que sólo cuando todo este mundo se derrumbe (y si no lo hiciere, habrá que acelerar violentamente esa caída), será hacedera la verdadera catástrofe, la catástrofe salvadora. Pues sólo con la absoluta disipación de las costumbres y la pérdida generalizada de la fe, e.d., con el advenimiento del Anticristo (una figura satánica, intercambiable según el bando), puede tener sentido la redención, que los pocos fieles elegidos habrán de recibir pasivamente. No sin morboso regocijo. En el Corán, con más fuerza aún que en el Apocalipsis johánico, se nos predice que: "los hombres, como moscas quemadas, yacerán en el suelo", mientras: "las montañas se desharán como lana deshilvanada (Sura 101); junto con devastadores terremotos, el firmamento caerá hecho pedazos sobre la tierra, la luna se partirá, y acaecerá el fin del mundo (Sura 66). Es más, la recopilación Sahih lleva al extremo el rasgo característico de toda catástrofe escatológica, a saber: la profunda desconfianza, el desprecio hacia el carácter sensible y terrenal del hombre y de las cosas. Pues es este negro peso de tierra, interiorizado en el hombre como carne, lo que impediría la fidelidad absoluta a Dios, la conjunción con lo eterno. Por eso, según la mentada recopilación coránica, a un toque de trompeta todos los hombres morirán (incluidos, pues, los fieles), y el

34 Originalmente publicado en J. Pardo (ed.), Historia y catástrofe. Cuaderno Gris (10) / UAM. Madrid 2012 (Contr.: Catástrofes mínimas en las artes y la poesía, 167-180).

35 Die Grundprobleme der Metaphysik. Klostermann. Frankfurt/M. Gesamtausgabe 29/30, 243. 
mundo entero será aniquilado. Sólo quedará Dios, y su cohorte angélica. Luego de un segundo toque, a cargo del ángel Israfil, resucitarán los muertos, prestos a escuchar el veredicto del Juicio Universal. Acto seguido tendrá lugar una nueva creación sempiterna, de la que ésta, la nuestra, habría sido un mal remedo (un acusado rasgo gnóstico se dibuja aquí), una suerte de campo de pruebas. Por lo demás, ello habrá de suceder enseguida, tras la conquista del mundo por el Islam.

Frente a esa catástrofe universal, preparada y provocada por el irremediable desarreglo histórico, la muerte propia, la muerte individual, debiera ser considerada en cambio como una catástrofe mínima: una especie de cancelación de una perspectiva singular, inapreciable, négligeable desde el conjunto de la Creación. Más aún, frente a la semítica, la sabiduría trágica de los griegos considera más bien un dispendio, un derroche insensato, provocado por un destino justamente ciego, la existencia de este mundo, y de los hombres en él. Pues la vida de verdad está en otra parte, ajena a las inclemencias del dolor, del sufrimiento y de la vejez. La catástrofe es ya esta vida sensible, ordinaria, que ha de ser soportada reduciendo todas las emociones violentas, sean agradables o dolorosas, a un sabio y prudente término medio (méden ágan): vivir como si ya se estuviera de algún modo muerto, a la espera de la restauración del orden, a la espera de la katastrophé. Por cierto, no deja de ser significativo el hecho de que, así como el término "apocalipsis" ("desvelamiento, revelación") ha perdido por entero su valor positivo, redentor (ilo importante no es el -por otra parte ansiado- fin del mundo, sino la visión de la Verdad que él velaba!), así también la voz "catástrofe" se ha teñido de resonancias aterradoras, de algo ineluctable, ante lo cual está el hombre absolutamente inerme, hasta el punto de que apenas si somos capaces de oír-leer lo latente en el término griego de origen.

Katastrophé significa literalmente: "trastorno, cambio de arriba abajo"; en la tragedia griega, se mentaba con ese término el desenlace de la obra, generalmente luctuoso, pero en el que -por ello mismo, por el sacrificio del héroe- se restablece el orden y el sentido. Figuradamente indica el "cese" o la terminación de algo, y, por excelencia, la muerte del hombre. ${ }^{36}$ La palabra se compone de la preposición katà: "de arriba abajo" (como en "categoría": el fallo o sentencia que se impone al reo: lo que él es de verdad) y de strophé (nuestra "estrofa"), una sustantivación del verbo strépho: "volver, hacer volver, torcer"; a veces, con violencia (de ahí que pueda significar también "torturar": de nuevo, entresacar al reo la verdad que él quiere ocultar); en sentido neutro, significa "dar una vuelta", "cambiar de camino". ${ }^{37}$

La katastrophé es pues un cambio brusco que a algo o a alguien le sobreviene, sin que esté en su mano preverlo ni prepararlo, y que supone un retorno: una vuelta al origen y, con él, a la verdad. De ahí la sabiduría de Sileno, transmitida famosamente por Cicerón: el rey Midas habría encontrado una vez borracho a Sileno (era por demás su estado habitual), el ayo de Baco. Tras capturarlo, el rey lidio exigió para su liberación que el sátiro le revelase la verdad suprema (o sea, le pidió la apokalypsis). Vertida al latín ciceroniano, la respuesta reza así: "no haber nacido es, para el hombre, con mucho lo mejor, o bien, morir cuanto antes" (non nasci homini longe optimum esse, proximum autem quam primum mori). ${ }^{38}$ No es extraño que la sentencia provenga de un ser híbrido, participante de la naturaleza animal y de la divina. Sileno conoce los dos mundos, y sabe cuál es el verdadero. Por lo demás, esa "revelación” estaba muy extendida en el pensamiento griego. La encontramos también mucho tiempo atrás, y revestida de mayor dignidad. En este caso, es el coro trágico quien la pronuncia, dirigiéndose a aquellos insensatos que quisieran -en vano- prolongar su vida. Pues cuanto más viejo se es, tanto más aumenta el dolor,

36 C. Alexandre, Dictionnaire Grec-Français. Hachette. París 1878, p. 757.

37 Ib., p. 1322. Strépho, a su vez, está emparentado con trépo: "regresar", pero también "transferir, transportar y transformar." De ahí el sentido del tropo o "giro".

38 M.T. Ciceronis Tusculanarum Disputationum liber I,XLVIII, 114. 
entendido como una caída en un lugar o situación distinto al que uno se propone. Por fortuna, sigue el coro, a desbaratar ese soberbio delirio nos ayuda la Moira del Hades, al presentarse austeramente: sin himeneos, sin liras y sin danzas, en el momento supremo. Y entonces se revela la verdad:

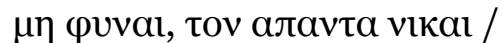

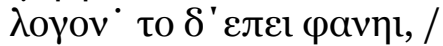

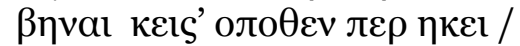

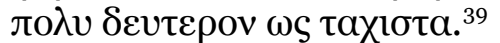

("No haber nacido: tal es la sentencia [el lógos] que a todo vence. Pero ya que se ha venido a la luz, lo mejor en segundo lugar es, con mucho, volver cuanto antes allí de donde se vino.")

Con todo, algo nos dice que -incluso para el griego- difícilmente podría pasar tal sabiduría por un mensaje de salvación. De atenerse al contexto del coro sofocleo, más bien parece tratarse de un hiperbólico mecanismo de compensación. Si ya han pasado los dorados días del placer, si la vejez amenaza con sus achaques, ¿no sería ridículo pretender seguir viviendo, ahora que ya es casi imposible el goce, es decir el bello ajuste entre mi propósito, mi acción y el resultado de ésta? $\mathrm{Si}$, como dice el coro, "se ha venido a la luz", la cual ilumina un mundo variopinto, cambiante y siempre sorprendente, ¿cuál podría ser entonces el mundo más acá de la luz, el mundo del Origen y de la Verdad al que la muerte nos devuelve?

Dejando a un lado el mítico cortejo cinegético de las almas bienaventuradas en el Fedro platónico (las cuales se limitan a ver mejor y en directo, live, lo que nosotros vemos como sombras en la caverna y en diferido, lo cual vuelve a privilegiar la luz y la visión), o la no menos mitológica elección de destinos post mortem en el libro X de La República, cuando el filósofo quiere tratar por lo derecho, en serio y sin imágenes, de lo verdaderamente verdadero, escribe que el embozado Sócrates le dice al hermoso y deseado Fedro que el famoso tópos hyperouránios está ocupado por una "realidad que lo es de verdad, sin color alguno, sin figura e intangible" (achrómatós te kaì aschemátistos kai anaphès ousía. Phaidros, 247 C). iAsí que ésa es la Verdad verdadera, el òntos òn! Dicho de una manera un tanto cínica (o melancólica, según se mire): puesto que no podemos gozar continua y regularmente de nuestros sentidos y del goce que proporcionan, lo mejor será desconectarse de ellos, y del mundo que a ellos se abre. Sin resto.

Pero, ¿qué puede ser eso que resta luego de quitarlo todo? Si al cabo no tenemos ya ningún residuo, es decir, ninguna advertencia relativa a la imposibilidad última de conjunción entre lo externo y lo interno: ningún aviso, en definitiva, de muerte, ¿qué podrá ser eso que es puramente inteligible sino la resta o sustracción pura de todas las diferencias que componen la realidad? Platón exige exige al varón que se sujete a esa ousía inefable: a un eîdos no-sensible (anaisthetós; entiéndase bien: no simplemente por encima de lo sensible -eso, todos los eîde lo están-, sino activamente negador y depurador de lo sensible). Sólo con esa cosa pura por amorfa, anti-sensible, podremos pasar luego a establecer criterios en la realidad, según las cosas se vayan acercando a ese baremo supremo. Y todo ello con una sola finalidad: lograr la autarquía con respecto, no tanto a la naturaleza, cuanto justamente al tiempo, al envejecimiento y a la muerte; respecto a todo aquello que nos hace distintos, diferenciales, todo aquello que nos sobra. Justamente, nuestros restos.

Ahora bien, ¿qué es un resto, un residuo? La respuesta es obvia: es lo que queda tras

39 Sófocles, Edipo en Colonos, vv. 1224-1227. 
el goce, la dolorosa constancia de que no todo es asimilable, de que existe un desajuste primordial entre los dos fondos a partir de los cuales existimos: el nuestro propio, al que podemos llamar "carne", y el de la realidad externa: la "tierra". Mas entonces se alza la sospecha: ¿no será precisamente ese desajuste, ese resto irreductible, irreciclable, la catástrofe mínima, en lugar de la muerte? La muerte-katastrophé de Sileno, la muerteê̂dos anaisthetós de Platón (o el umbral que conduce a esa ousía amorfa e incolora: para el caso es igual), ¿no será entonces un intento por parte de poetas y de filósofos de borrar o al menos de ocultar, no tanto la muerte propia o las catástrofes de la historia y de la escatología, cuanto la constante, inevitable recaída en la descomposición, en lo que está de más? De más, hasta que yo mismo lo esté también, enteramente.

¿Qué se obtiene empero con esa ocultación? Se obtiene... tranquillitas animi, desapego respecto de las cosas, de todo fenómeno vistoso: pues lo que el sabio dice ver ahí debajo (o por encima, o por detrás, que aquí las dimensiones espaciales empiezan a girar vertiginosamente) es algo que no ofrece ya resistencia alguna: puesto que no tiene figura, color ni dureza, puede ser entonces considerado como puro plasma, como algo a ser conformado, moldeado y mensurado ad libitum por el hombre. Un estridente hilo rojo nos lleva así del òntos òn platónico al morceau de cire cartesiano y de éste a la plástica de posguerra, especialmente al minimal. Sólo que el griego se contentaba con apaciguar el deseo al máximo, intentando escudriñar en cambio algo absoluta y literalmente impresentable (y no sólo el griego: recuérdese la luz que emana de la candida rosa de la Divina Commedia o, ya sarcásticamente, de la puerta abierta en Vor dem Gesetz, de Kafka). Por el contrario, Descartes, matemático y magister de ingeniis, no se contenta con contemplar una realidad de base, existente más allá de fenómenos y de mortales. Más bien es él quien crea esa realidad, a la vez categórica y catastróficamente: categóricamente, puesto que se apoya en el acies mentis y las coordenadas matemáticas que de él resultan; catastróficamente, puesto que procede sistemáticamente, de arriba abajo, a desconectar con violencia, como en un ejercicio de tortura (una de las acepciones de katastrépho, recuérdese), todo lo sensible, hasta dejar tan sólo un resto. La pluralidad, la diversidad inabarcable de los cuerpos es obscena. Su apropiación aún lo es más. Por ello, procede su disolución hasta llegar a una pasta única, extensa y maleable. Nuestro filósofo toma, exempli causâ, hanc ceram: esta cera in particulari. Ella presenta justamente las cualidades que Platón niega a su ousía: ejus color, figura, magnitudo, manifesta sunt, y además: facile tangitur, es "fácilmente palpable". "Pero he aquí -dice- que mientras hablo (dum loquor, recuérdese el victorioso lógos sofocleo), se le acerca un fuego." Es curiosa la actitud aristocrática del ingeniero: deja al trabajador manual la faena de la tortura. Y verbos de tortura y muerte son en efecto los que ahora aparecen en cascada: "los restos de sabor son depurados (purgantur), el olor expira (expirat), se muda (mutatur) el color, se suprime (tollitur) la figura [irecuérdese la ousía aschemátistos, F.D.]"; y en fin: "apenas se la puede tocar (tangi)." Pues bien, después de esta "limpieza étnica", se pregunta retóricamente Descartes si todavía "sigue permaneciendo allí (remanetne) la misma cera", para responder al punto que, eso, "nadie lo niega, nadie puede juzgarlo de otro modo." Pues en efecto, tras la operación, dice: remanet cera..$^{4^{\circ}}$ Bien puede ser. Pero será en todo caso "cera" en general -por no llamarla ya directamente res extensa-, y no desde luego haec cera. La cosa individual ha sido ofrecida en sacrificio a la mente técnica y matemática del hombre moderno, al igual que el héroe de la tragedia griega era la víctima que apaciguaba a los dioses.

Es verdad que la física matemática de la primera modernidad dejaba aún todo (desde el respecto sensible, ad limitem absolutamente todo) lo eliminado de la ousía-res extensa al cuidado del arte: un "cuidado" bien interesado en el "reciclaje". Pero la

40 R. Descartes, Meditationum de prima philosophia II. Adam-Thannéry VII, 30. Vrin. París 1967, p. $30 \mathrm{~s}$. 
suntuosidad y el brillo de los colores en Rubens o Rembrandt no debieran ofuscarnos hasta el punto de no dejarnos ver la estrecha complementariedad existente entre el arte y la ciencia, en el barroco. Pues si ésta tiende a suprimir la individualidad e irreductibilidad entre las cosas, la intuición barroca, por su parte, desgarra, desplaza al hombre de su asentamiento en el mundo y lo suspende por así decir de la grisalla del vacío, como se aprecia en los cuadros de Caravaggio y de Velázquez. La grandiosidad de los decorados teatrales, la ampulosidad de las fachadas barrocas y de los monumentos funerarios, la "carnosidad" y pastosidad en fin de la pintura, desde el sfumatto al tenebrismo de Ribera o de Zurbarán: todos ellos son signos que muestran, a sensu contrario, el sinsentido de la vida (un sinsentido que nosotros vemos apuntar ya incipientemente en algo aún más peligroso para la época: la inanidad, no sólo de "esta" vida terrenal, sino de la vida "eterna", cuya única "consistencia" -como venimos comprobando- estribaría en su función destructora del mundo, como un fuego que vive y se consuma en el perenne incendio de lo existente).

La inversión barroca de los planos, presente por igual en el ámbito protestante y en el de la Contrarreforma, consiste como es sabido en ver a esta vida como muerte, y a la muerte como umbral de la vida "verdadera". Sirva como ejemplo de este "catastrófico" quiasmo la sepultura del arquitecto Giovan Battista Gislenus, en la iglesia de Santa Maria del Popolo, de Roma. En ella, el difunto está retratado en lo alto, mientras abajo un esqueleto esculpido sostiene la leyenda: Neque hic vivus, neque illic mortuus. ${ }^{41}$ Llevemos al extremo el significado de estas palabras, generalizándolas: ellas no dicen simplemente que Gislenus, ahora muerto, esté simultáneamente viviendo de verdad "al otro lado", tras pasar el umbral de la muerte. Ese hic no se refiere sólo al "aquí" del sepulcro, sino a la vida en la tierra: mientras creemos estar vivos, en realidad estamos muertos; y al contrario, illic: "allí", en ese "lugar" al que llamamos muerte, se está dando la verdadera vida. Concedámoslo. Pero, ¿dónde se da cuenta de esta inversión? Neque hic, neque illic: "Ni aquí, ni allí". Ése es el impensable "espacio" abierto por la obra, la intuición del paso, del purísimo movimiento de la existencia, todo él tensión de dos fuerzas contrapuestas, las cuales sólo dirían su verdad si per impossibile pudieran descansar cada una en su opuesto.

La obra barroca es imagen, pero ¿̇de qué? En nuestro caso, ¿dónde estará el "original”, es decir: el propio Gislenus? ¿Está representado en el retrato, o bien simbolizado por el esqueleto, o acaso estará de cuerpo -o mejor, de polvo y ceniza- "presente" en el sepulcro (como un resto), o en fin como gozosa alma en el paraíso (un alma entendida también ella como lo que "resta" de un supuesto compositum carnal-espiritual, perdido para este mundo)? En verdad, Gislenus está diseminado por todos esos lugares, en virtud del "no-lugar" que es la obra. Ésta pretende articular una totalidad, mas precisamente en su ejecución la destruye y fragmenta: todo aquello a lo que la obra se refiere se torna en residuo, en ruina. Sólo ella, la obra, queda incólume, como guarda de la ruina: instauración in absentiam de la "brecha" o el vano a través del cual se atisba la fragmentación de una totalidad de sentido que la obra de arte pretendía instaurar.

Por ello, el arte del Barroco supone una amenaza para la supuesta y deseada conjunción de esferas de la Modernidad: la representación de lo sensible deja sin sentido a lo sensible en su propia manifestación.

Adviértase que, de este modo, la imagen expulsa de sí, rechaza no tanto al hombre y las cosas, cuanto a su conjunción en el goce o su destrucción en el dolor o en el desgarramiento. Con toda su pomposa altisonancia, la imagen abre la brecha del intervalo.

Pues bien, en el siglo XX, al cabo de la calle tecnocientífica, se intentará continua y obstinadamente obturar formalmente esa brecha mediante las distintas oleadas del suprematismo, del constructivismo y del minimalismo, exaltando una manera puramente,

41 He tomado el ejemplo de Mario Perniola, La societá dei simulacri. Cappelli. Bolonia 1983, p. 95.

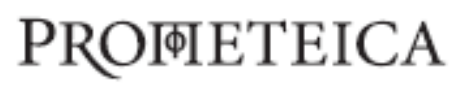


racionalmente geométrica de desustanciación de la realidad. La imagen debe desaparecer, porque incluso en su ambigüedad deja ver la muerte. Como reconocerá abiertamente Dan Flavin, hablando en 1967, del minimalismo: "Estamos presionando hacia abajo (ijusto como una katastrophé!, F.D.) hasta la ausencia del arte (towards no art) -un sentido mutuo de decoración psicológicamente indiferente-, un placer neutral de la visión, accesible a cualquiera." ${ }^{2}$ iEsto sí que es verdadero "platonismo para el pueblo"! Ya no es necesario expulsar a los zoógrafos de la Ciudad, dado que éstos se han convertido -tras tomar cursos acelerados de tecnociencia- en geómetras iconoclastas, verdaderos exorcistas del goce y del dolor: los amigos de lo neutro. Allí donde ninguna catástrofe puede tener ya lugar, donde ya no hay muerte... porque tampoco hay vida. Solamente serialidad, repetición, módulos indefinidamente ensamblables y desmontables.

De ahí la revuelta que, junto con la pintura posmoderna americana de Julian Schnabel y David Salle o el neoxpresionismo alemán de Georg Baselitz y Anselm Kiefer, supuso la llamada transvanguardia italiana, explícitamente enderezada -según su mentor y propulsor, Achille Bonito Oliva- a la "producción de catástrofes", entendidas de un modo similar al del événement lyotardiano: como una "accidentalidad no planificada", una suerte de stásis del discurso, de interrupción brusca que deja ver, justamente a través de la figura, la tierra de lo imaginario, frente al simbolismo y al subjetivismo del expresionismo abstracto. ${ }^{43}$

La exaltación del placer está señalada en la declaración misma de principios de la transvanguardia: contra los formalismos de la vanguardia hasta los años 70, las catástrofes mínimas de este movimiento se habrían esforzado en dar "respuesta a la catástrofe generalizada de la historia y de la cultura”, o sea: a esa catástrofe denunciada por Heidegger a finales de los años 20. Pero no se pretende ya acabar con la catástrofe (y menos, mediante otra: p.e., la revolución), sino soslayarla sin intervenir en los grandes debates sociales (la transvanguardia se inscribe al respecto plenamente en el cinismo narcisista posmoderno) y exaltando en cambio el valor del erotismo en la imagen figurativa: "una imagen que no se prive del placer de la representación y de la narración."44

Y sin embargo, lo que, por ejemplo, nos presentan la pintura de Schnabel, la de Salle o la de Francesco Clemente, con su neomanierismo y su juego de citaciones -convertido en Salle en tachaduras y graffitti- es justamente la rotura de toda imagen, de todo placer, de todo goce. Es como si estas catástrofes mínimas estuvieran contagiadas de esa gran catástrofe cuya exorcización pretenden. Al cabo, la transvanguardia -dejando quizá a salvo la autodescomposición de las obras últimas de Clemente-, parece desembocar en una reacción a toda vanguardia: más lúdica y desvergonzada, sí, pero en todo caso paralela, o mejor: como una vuelta más de la espiral de ese "retorno al orden" que a partir de los años 20 preconizara Giorgio de Chirico, su gran antecesor.

¿Qué ha ocurrido aquí? Creo que habremos de ir a buscar siquiera el esbozo de una respuesta no tanto a los terrenos de la pintura neofigurativa y su enconada lucha con la plástica, cuanto a los de la filosofía y la poesía.

Anteriormente se había ofrecido una descripción -más que una definición- de catástrofe mínima, entendida como el resto -y la reacción ante él- que deja la

42 Cit. en Suzi Gablik, "Minimalism“. En: Nikos Stangos, ed., Concepts of Modern Art. Thames \& Hudson. Londres 1995, p. 244.

43 Cf. A. Bonito Oliva, The Italian Trans-Avantgarde. FLASH ART INTERNATIONAL (oct.-nov. 1979), 17-20

(respect. p. 17 y 19). Cit. en A.M. Guasch, El arte último del siglo XX. Del posminimalismo a lo multicultural. Alianza. Madrid 1999, p. 275, n. 12 y 14.

44 A. Bonito Oliva, "Italiana 1950-1986", en su catálogo homóinimo. CIMAL INTERNACIONAL 9 (1986) 23; cit. en Guasch, p. 276, n. 20. 
cumplimentación del deseo. Adviértase: la catástrofe acontece en esa cumplimentación, no en su frustración o dilación. Cosa extraña, y de no poca monta. Analícemosla con cuidado.

Llamamos "goce" a la consecución de un placer, mediante el cual me he abierto a lo otro. Pero esa apertura marca, rasga y hiende. De ahí que tendamos a posponer el goce artificiosamente, creando una dilación, una demora. De este modo, el deleite queda asumido (aufgehoben) por su representación: mantenido a raya, a distancia. La mano no palpa ni acaricia la cosa deleitable, sino que la rebaja: niega su existencia, transforma violentamente su aspecto, la trabaja, en suma. Y no estoy pensando exclusivamente en la conversión de una cosa natural en producto (digamos, de un árbol en mesa), sino en algo más brutal y a la vez refinado; algo a lo que Kant llamaba Cultur. Es la cultura por la que el pintor roba el alma y la vida de la pobre novia de The Oval Portrait, de Poe, al plasmar sus facciones en el cuadro; el mismo proceso por el que el enloquecido Hoffmann asiste impotente a la muerte de Antonia, arrebatada por su propio, incesante canto.

Pues bien, la cultura aleja a la cosa, la hace indisponible: objeto de deseo. Y el intervalo entre el goce frustrado y la posesión de la cosa es el tiempo futuro: el ámbito de lo posible. Por otra parte, el conocimiento de que yo podría haber experimentado un goce, sin sentirlo por ahora, provoca un recuerdo: tiempo pasado. En el presente se cruzan el dolor de lo ausente y la esperanza de lo futuro. En el presente hace acto de presencia una representación, una imaginación susceptible de ser comunicada.

El deleite es individual, porque su goce no se da en el tiempo, sino que se realiza al instante. Los deseos, en cambio, son compartibles, comunicables. El deseo mancomuna: nos hace falta. Esto es: sentimos su falta como si fuera una falta, y más: una marca, necesaria para (que seamos) nosotros. Propongo que se tome esta expresión al pie de la letra: el deseo establece un corte, una catástrofe mínima en el continuo magmático de goce/deleite y dolor/destrucción que llamamos vida. Los animales se integran y desintegran en este continuum. Sólo el hombre tiene tiempo, no para el deseo, sino en virtud del deseo. $\mathrm{Si}$ cumplimenta sus deseos, mata el tiempo. Por fortuna, hay deseos de sobra: cuando unos desaparecen, saciado el sujeto, otros advienen en oleada. Y entonces surgen de ahí tiempos sueltos, heterogéneos.

Hay cosas que a uno le apetecen (y aparece así en la proposición indirectamente, como un complemento). La apetencia es impersonal, disuelve. Pero cuando yo digo: "deseo tal cosa", en el fondo estoy quitando a la cosa su propio peso, guardando de ella sólo su representación como posibilidad de reparación de una falta. Sólo que en el deseo no pongo la fuerza necesaria para apropiármela, sino que dejo ser a su exangüe fantasma, a la huella que su falta dejó en mí. La cosa, en el deseo, brilla por su ausencia. Es puro brillo, Schein. La cultura se aferra a ese brillo y, así, fragua un espacio y tiempo comunes, pues lo que reluce y alumbra crea comunidad. El sol sale para todos.

Pero puedo ir desde luego más allá y decir: "quiero tal cosa". Aquí hay imperium, seguridad del goce, paso a la acción asimiladora, negadora del objeto, en suma. De ahí que los hombres de mando y poder -no digamos si el mando se tiene sobre las armas, es decir, sobre la posibilidad de anticipar la muerte- desprecien a los hombres de cultura, soñadores inactivos, tejedores del deseo. Claro que sin tal tejido no existirían cosas que dominar y, a veces, destruir.

Tenemos, pues, apetencia animal, deseo humano, voluntad personal. Si queremos, bien se puede decir que por lo primero somos "ello" (id), por lo segundo "yo", por lo último "super-yo". Sólo en el segundo caso hay tiempo y convivencia. Se muere uno de ganas de experimentar placer, para el que siempre le falta a uno tiempo. Le sobra en cambio tiempo al sabio -o eso se cree él- para pensar y ordenar correrías y desvelos de los hombres. El deseo, en cambio, es el ojo del huracán en que se sume nuestra vida.

Los estoicos fueron muy sutiles en esta distinción entre deseo y apetencia, que lenguaje y vida común emborronan (y habrá que preguntarse de dónde viene ese borrón). 
Cicerón nos cuenta que, según esta doctrina: "hay deseo de aquello que se dice de algo o de algunas cosas, y que los dialécticos llaman kategorémata" (libido sit earum rerum, quae dicuntur de quodam aut quibusdam, quae kategorémata dialectici appelant). En cambio: "la codicia se debe a las cosas mismas" (indigentia rerum ipsarum est). ${ }^{45}$ Adviértase que, en el primer caso, hacemos de las cosas predicados: vienen así elevadas a lenguaje y representación (recuérdese, además, la alusión anterior, sobre la cercanía entre categoría y catástrofe). Todo deseo es, en el fondo, ganas de ver y ganas de hablar. La indigentia, por el contrario, es codicia de las cosas mismas.

Pues bien, el hombre qua hombre no codicia nada: de todo hace teatro. Así, no debe decirse que en verdad deseamos el sexo, la comida o el dinero. En el sexo, lo que deseamos realmente (tapándolo púdicamente con las quisicosas de la procreación) es la constatación consciente -y en el tiempo- de una sumersión inconsciente que está más acá del tiempo. Deseamos la imposible vivencia de estar muertos; la vivencia, controlada y efímera, de la mortalidad: que yo vea cómo dejo de ser para fundirme con ese ser que antes me era ajeno. Yo desearía que el tiempo, aquí, se tornara en instante. Mas siempre es ya demasiado tarde para "ello", demasiado tarde para que el Yo cortante y determinante vea la continuidad de la carne. Esa dejadez abstracta, ese resto vencido de la inaccesibilidad del instante, es el "ahora". El presente puntual es el don de una derrota: nunc stans. Ahora es ya: el espacio mediante se escapa del cuerpo, fluido.

En la comida, en la ingestión de lo extraño (ya no en la extensa y superficial contingencia de la frontera dérmica), se pretende llenar un hueco, reparar una pérdida: ser sí mismo a costa de un precario equilibrio entre adquisición (lo que todavía no se es) y desechos (lo que ya no se es). No el hambre y la sed mismas, sino el decir y ver que tengo hambre y sed engendran pasado y futuro. Sexo y alimento son objeto de codicia, de apetencia.

El dinero, en cambio, no le apetece a nadie (como nos recuerda un conocido aviso de los verdes ecologistas, el dinero no se come). El dinero mismo es ya flujo y corriente universales: el curso en que se entremezclan tiempo, trabajo y lenguaje de los hombres. Objeto purísimo del deseo, el dinero da valor a las cosas: les da un peso exclusivamente humano, el peso de la sociedad civil. Por eso engendra la irreversibilidad corriente del tiempo: nunc fluens.

Por el sexo hay individuo, salvado justamente al borde de su precipitación y ruina: él es lo que queda, el resto del naufragio orgásmico; por la comida, difícil convivencia de lo heterogéneo: conciencia de la vida. Sólo por el dinero hay, en cambio, oikonomía: regulación y ritmo del commercium común de apetitos y agresiones; y, en esa escansión, hay sociedad. Individuo, vida, comunidad: tres abstracciones para un mismo deseo. Tres frustraciones también, indisolubles de lo anterior, que abren a una misma catástrofe mínima.

Pues en verdad no se desean, lo hemos visto, otros cuerpos, alimentos, dinero u honores. Se desea su posesión, esto es: demostrar al mundo quén manda aquí. Por eso, el Yo es resultado y referente del deseo, pero ya estaba de siempre a su base, presupuesto.

El Yo, el sujeto del deseo, no entra en posesión directa de las cosas que uno apetece. De hecho, esa inmediatez le asquea: mano, vista y boca guardan en cambio las distancias: en nuestra mano están, más bien, educadas y redichas, las representaciones, dócilmente convertidas hoy, más allá de los signos, en simulacros.

¿Dónde ha quedado entonces, tras este transporte, nuestra mano carnal, dónde nuestro cuerpo? Como siguiendo un exacerbado noli me tangere, ahora mismo estoy rozando apenas con la punta de mis dedos teclas levemente rugosas. La idealización de la realidad arrastra en su licuación a la propia membrana osmótica: In carne enim ambulantes non secundum carnem militamus, según la divina divisa del Apóstol de los gentiles (2 Cor. 6,5). Limito a lo imprescindible el intercambio con lo ajeno, porque me acabo de dar cuenta de que el trance del placer no está en la cosa ni en el Yo, sino en el paso. Es el transitus mismo, 
desnudo, el que provoca la voluptuosidad, advierte sobresaltado San Agustín. ${ }^{46}$ Y es que, en la transición, dejo de ser yo: estoy como al borde, al margen de mí mismo. Los ojos se salen, la piel se estremece. Ni dentro, ni fuera. Ni en lo necesario (mi Yo), ni en lo real (las cosas), ni en lo posible (las representaciones). El extraño escenario donde me hallo -angosto como el filo de un cuchillo- bien podría denominarse la con-tingencia, la co-tangencia o contacto: lo que es, pero bien podría no ser, sin que nada pasara. Lo dejado de la mano del Yo. Puro umbral del instante. Y sin embargo, aquí no hay fusión ni confusión. El placer viene, inminente. Cuando acontezca, habrá un continuum: no pieles en contacto, sino carne y aun, al cabo, licuefacción, flujo. Pero todavía no. De manera que, en el fondo, nunca hay autosatisfacción: de ahí la tan cínicamente denostada tristeza de la carne. Y de ahí también, dicho sea de paso, el carácter meramente exhibicionista -por no decir tiernamente estúpido- de la performance de Vito Acconci, empeñado en masturbarse (o en simularlo) durante horas, tendido debajo de un tingladillo, en la creencia de que esa "Cama semilla" (Seed Bed, 1972), le iba a permitir establecer una communio -simbólicamente carnal- con el público. ${ }^{47}$ Eso no es una catástrofe mínima, ni siquiera una petit mort. Sólo un vacuo gesto que se consume en su inanidad.

$\mathrm{Al}$ igual que en el fementido momento de la muerte, antes del placer estoy a solas con mi ansia, sin el objeto; después de él, me siento atado al objeto de un placer muerto. Mi cuerpo y el cuerpo: despojos del Deseo. El uno, ruina; el otro, monumento. Por eso está asqueado el Santo de ese diario andar reparando, mediante la comida y la bebida, las ruinas corporis $^{48}$ : que ruina es pérdida, merma. Y la reparación, reconocimiento desganado de que la verdad -la verdad de mi cuerpo, al menos- está fuera, en el alimento. Confesión de que él, este cuerpo que llamo mío, es ya lo otro. Siempre lo fue. ¿No se llama acaso igual que las otras cosas: corpus, cosa neutra? Y sin embargo, San Agustín siente en el alma el punzón de la indigencia, de modo que lo que de veras desea es que Dios destruya de una vez comida y vientre -cuerpos y cuerpo-, que mate a la indigencia con la saciedad y que haga, en fin, de lo corruptible temporal incorruptibilidad sempiterna.

La satisfacción de los deseos, ¿consistirá pues en una absoluta negación del Deseo? El miedo a las pérdidas (en definitiva, el miedo a la muerte, al transitus completo al exterior), ¿se vence con la Muerte? Y si no es el Cero Absoluto, ¿en qué consiste tal sacietas mirifica? ¿No ronda aquí de nuevo la amorfa aparición de la ousía platónica? No, porque, en un sorprendente viraje, para San Agustín la vita beata sería algo como una cumplimentación simultánea de todo placer: algo así, nos dice en La ciudad de Dios, como la vida de la esponja en el mar: transida, traspasada de parte a parte por la Divinidad, sin confundirse empero con ella. Ahora, el flujo no sale: penetra por todos los poros del alma. Pura pasividad. ¿A eso llevaba el ansia de posesión y dominio? ¿A empaparse de una viscosidad chorreante?

¿Qué es esto sino la saciedad de toda indigencia, el anhelo de San Agustín? Al final no falta nada, porque nada hace falta. Se acabó la monstruosa cabalgata de lo sensible: "De aquí que por la continencia nos recojamos y restablezcamos en uno, a partir del cual nos habíamos derramado en muchas cosas" (Per continentiam quippe colligitur et redigimur in unum, a quo in multa defluximus). ${ }^{49}$ Así pues, se acabó también ese nuestro irnos derramando por las cosas, tiñéndolas de nuestros deseos, elevándolas a posibles. La continencia comprime, consolida, haciendo refluir el flujo. Ya somos, al fin, unum. O sea, hablando con todo rigor: nada de particular.

Pero no es eso, no es ese unum neutrum lo que yo deseo. En castellano, "deseo" ha sido derivado -nadie lo dijera, al pronto- del latín vulgar desidium, procedente a su vez del clásico desidia: una dejadez, un quedarse sentado, inactivo, "viéndolas venir". Desidia, cante

46 Confesiones. En: Obras. Ed. A.C. Vega. B.A.C. Madrid 1968, p. 429.

47 "El público, oyendo mi voz, se fija en mi actividad [...] es encontonces cuando el público, en el espacio de la galería, se une con mi espacio privado y llega a pensar: ha hecho esto para mí, lo ha hecho conmigo, yo lo he hecho con él. En L'art au corps ; cit. en Guasch, p. 96, n. 30.

$48 \quad I b .$, p. 428.

49 Conf. X, 29; p. 426. 
qué, sino ante la estéril fugacidad del goce, del pequeño placer sensible, siempre sustituido por otro al instante de su consumación? La desidia implica pues una suerte de desprecio hacia la realidad y, por ende, un ansia de representación, de imagen que fije el instante. Al contrario de lo habitual, el deseo como desidia ve en lo sensible una huella de lo imaginario. Y va en pos de esa huella.

Si seguimos el recurso de esa huella iremos a parar a una extraña región, en la que no se nos devuelve el pasado (porque la cosa tras cuya huella vamos ya ha sido) ni se nos presenta el futuro (porque ella todavía no es). Lo que allí vemos es, en efecto, que "todavía no": vemos el nondum ciceroniano. Non-dum: "no... mientras", "no... durante todo el tiempo en que algo sea". El deseo deja a los cuerpos llagados, pues marca el transcurso del tiempo con la huella del instante perdido. Es verdad, como apuntamos antes, que la representación hace sociedad, que abre habla y hace tiempo. Mas lo hace desde la extensión indefinida de una pérdida, de una ruina:

\author{
Eras, instante, tan claro, \\ Perdidamente te alejas, \\ Dejando erguido el deseo \\ Con sus vagas ansias tercas. ${ }^{50}$
}

El deseo es el ahora, entendido como huella del instante. Un ahora que se derrama en el pasado (abre la lejanía de la pérdida) y se yergue, oteando futuro, de manera indeterminada y, por tanto, abierta a tremolaciones siempre diferentes del acorde perdido. Así que la manera auténtica de desear no sería la segura de quien "está al tanto" y, por ende, cierra el futuro, sino la de quien deja erguido el deseo, como centinela del cuerpo, mirando desesperadamente hacia atrás, ansiando dar la vuelta y darse cuenta de sí mismo en la propia acción de volverse.

Sólo que es demasiado tarde para volver. El origen está ya a nuestras espaldas: consiste en lejanía. Si por azar volviéramos, comprobaríamos con dolor que ese ya no es nuestro origen. ¿Dónde habita el origen en cuanto origen? No en el recuerdo, no en la memoria: lo que a ella se presentan son eventos pasados, sueltos, que apuntan todos ellos a un origen, sin serlo. El origen estará donde habite el olvido, en ese lugar:

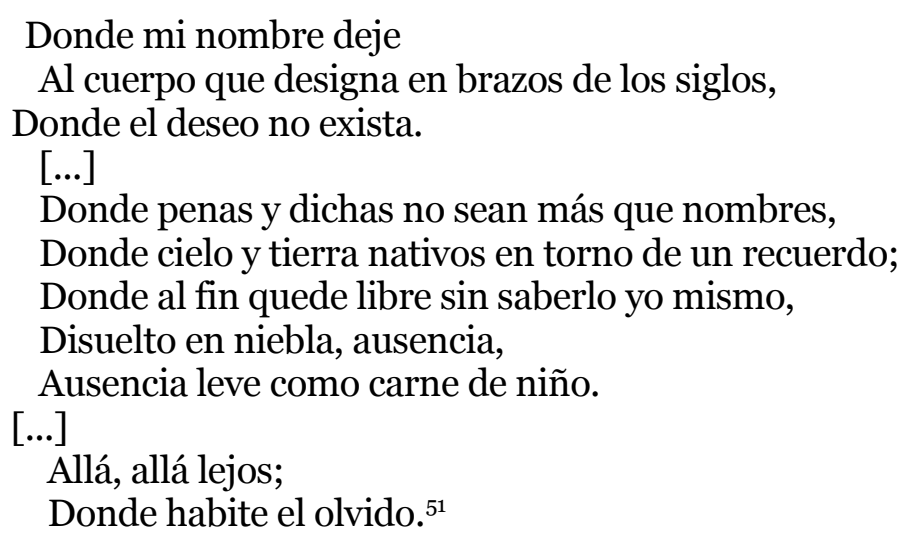

50 Luis Cernuda, Primeras poesías. XII, $1^{\mathrm{a}}$ estr. En: Antología poética. Ed. de R. Santos Torroella. Plaza \& Janés. Esplugas de Llobregat 1978, p. 35.

51 Donde habite el olvido. I, estr. $2^{\mathrm{a}}, 5^{\mathrm{a}}$ y $6^{\mathrm{a}}$. En la Antología citada, pp. 86. 
Pero, con ello, ¿no hemos vuelto de nuevo al refugio seguro -literalmente indeseable- de San Agustín? ¿Acaso se desea, en el fondo, no desear nada, olvidar el sobresalto de las penas y las dichas? ¿No alienta aquí de nuevo la tentación nihilista que venimos detectando desde Platón? Sí, en efecto. Sólo que importa mucho no confundir esta tentación con la del nihilismo del mundo interpretado, del mundo expuesto a las habladurías y el afán de novedades, y expuesto él mismo en ellas. En ese mundo, uno lo desea todo y, en el fondo, nada desea, porque todo da igual. El poeta, en cambio, desea la Nada, desea el acceso al Fondo mismo, y siente en sí la joie de descendre baudelaireana. Aquí no hay indolencia, sino desprendimiento. Es un exceso de deseo el que lo lleva al fondo:

\author{
Yo, el más enamorado, \\ En las orillas del amor, \\ Sin que una luz me vea \\ Definitivamente muerto o vivo, \\ Contemplo sus olas y quisiera anegarme, \\ Deseando perdidamente \\ Descender, como los ángeles aquellos por la escala de espuma, \\ Hasta el fondo del mismo amor que ningún hombre ha visto. ${ }^{52}$
}

El mismo "yo lírico" del poeta da testimonio de esta marea, contra la que ahora se desea luchar, refluyendo. Tendido entre el alfa y la omega, entre la voluntad y el entendimiento, entre el cuerpo y el hombre, la piel consumida en anhelo es así la sede del alma, como ya había apuntado Novalis: "La sede del alma está allí donde mundo interno y mundo externo se tocan. Allí donde ellos se penetran, allí está esa sede, en cada punto de la penetración." ${ }^{33} \mathrm{Y}$ es notable que se insista aquí en la sede como el límite o frontera en que cada uno lo es sólo si está ya en el otro: una superficie osmótica, pero en absoluto neutra, que se ahonda en desidia por su hondón interior, que se abre al asedio del exterior que en ella se agolpa. ¿Pura receptividad, pues? Sí, en el caso de que por tal entendamos la acción de salir al encuentro por parte del fondo. No todos los hombres tienen el valor de sucumbir activa, desinteresadamente a la desidia en la que se despliegan los deseos. Y aún menos ejecutan esa acción para bucear hasta la raíz misma del deseo. Una raíz fría, pesada.

Por el contrario, en el mundo desfondado, interpretado, la ambigüedad nos seduce por ramificaciones capilares, sin fin; son las pequeñas naderías de las que se excusaba San Agustín en sus Confesiones. ¿De veras se trata de naderías? ¿No serán esas pequeñeces más bien el último peccatum, la única "persistencia en la caída" de la que cabe acusar al hombre: el olvido del olvido, la indigencia de la carencia de indigencia? La única falta: la sensación de que ya nada falta. Sólo que esa caída brinda tranquilidad, apacigua, mientras que aleja... de uno mismo, del propio fondo. No nos queda al cabo sino una superficie sin fondo, tan blanda que no opone resistencia alguna a cualquier imagen, con tal de que sea sólo eso: pura imagen, sin nada detrás. En suma, es el hombre mismo el que, renegando de su fondo, se cierra a sí mismo los caminos, enredándose con cuentos y espectáculos.

Ese enredo es una emboscada, una insidia: tal es el término que vierte con toda precisión el carácter radical de la caída, en Heidegger: ser para sí mismo verfändlich, insidioso. Adviértase pues cómo deseo, desidia, asedio, insidia forman una constelación de sentido en la que queda prendida y a la vez desplegada la sede del alma.

Prendido el Yo, rico de deseos, en esa constelación, bien podrá entonces venir la muerte. No se llevará la fría pasividad de las verdades universales, sino el fuego contumaz de la pasión que identifica:

$52 \quad$ Ib., II, $2^{\text {a }}$ estr., p. 87.

Novalis, Blütenstaub [19]. En Werke. Ed.. H.-D. Dahnke. Berlín/Weimar 1983, p. 280. 
Cuando la muerte quiera

Una verdad quitar de entre mis manos,

Las hallará vacías, como en la adolescencia,

Ardientes de deseo, tendidas hacia el aire. ${ }^{54}$

Del hielo al fuego, del fondo a la punta de los dedos (una punta afilada, como una espina): es el deseo, que se derrama in multa, como temía San Agustín. Así pues, ¿todas las admoniciones, todos los sabios consejos de tantos siglos, han sido vanos? No. Creo que de algo hemos hecho la experiencia: la experiencia de la pasión. Y sólo a través de esas admoniciones podíamos hacerla, porque en su denuncia de insidias y emboscadas mostraban a las claras lo que deseaban a toda costa ocultar, a saber: que el unum neutro al que había que tender, retroductivamente, era el punto de partida, no el de llegada. No el resultado de la aspiración a lo mejor, sino la constante tentación de retorno al propio fondo a través de la indisponibilidad del otro, de lo Otro.

Deseo: libido de ver lo que todavía no es. Deseo de ser cuerpo, de ser sexo. Deseo de caída. Pero caída hacia arriba: hacia la superficie de los cuerpos. Catástrofe invertida. Una sola vez, y en un curso, dicta Heidegger las palabras siguientes, que quizá sean también señal de algo grande y de difícil interpretación: "a la esencia del Dasein, y de acuerdo con su concepto metafísico neutral, le pertenece ya una originaria Streuung que, en un respecto enteramente determinado, es Zerstreuung, disipación." 55 Streuung, sparsio: "derramamiento".

¿Y si el ser mismo del hombre fuera ya, ya de siempre, in aeternum, un flujo amorosamente encharcado en cuerpos hendidos, sexuados? Sólo quedaría por hacer, entonces, lo que de verdad habría que hacer: la guarda y custodia del deshacer, y del deshacerse. Y ello significa acariciar, habitar, contemplar las ruinas corporum en la superficie de la Ruina, del amasijo de residuos amorosos que llamamos Tierra. Delicadas, mortales catástrofes mínimas. Ahora, cuando estamos a tiempo. Todavía, cuando:

Sagrada y misteriosa cae la noche,

Dulce como la mano amiga que acaricia,

Y en su pecho, donde tal ahora yo, otros un día

Descansaron la frente, me reclino

A contemplar sereno el campo y las ruinas. ${ }^{56}$

54 Donde habite... VII; últ. estr., p. 90.

55 M. Heidegger, Metaphysische Anfangsgründe der Logik (SS 1928). G.A. 26, 172 s.

56 Luis Cernuda, "Las ruinas", últ. estr.. De: Como quien espera el alba, Op.cit., p. 165. 